\title{
Roles of Tetrahydrobiopterin in Promoting Tumor Angiogenesis
}

\author{
Liye Chen, ${ }^{*}$ Xin Zeng, ${ }^{*}$ Jihui Wang, ${ }^{*}$ \\ Simon S. Briggs, ${ }^{*}$ Eric O'Neill, ${ }^{\dagger}$ Jiliang Li, ${ }^{\neq}$ \\ Russell Leek, ${ }^{\ddagger}$ David J. Kerr, ${ }^{\S}$ Adrian L. Harris, ${ }^{\ddagger}$ \\ and Shijie Cai*

\begin{abstract}
From the Department of Clinical Pharmacology," and the Gray Institute for Radiation Oncology and Biology, ${ }^{\dagger}$ University of Oxford; the Cancer Research United Kingdom, ${ }^{\ddagger}$ Molecular Oncology Laboratories, Weatherall Institute of Molecular Medicine, University of Oxford, John Radcliffe Hospital, Oxford, United Kingdom; and the Sidra Medical and Research Center, Qatar Foundation, Doha, Qatar
\end{abstract}

Nitric oxide (NO), which is derived from endothelial NO synthase (eNOS), provides crucial signals for angiogenesis in the tumor microenvironment. Tetrahydrobiopterin (BH4) is an absolute requirement for eNOS activity. In this study, we investigated whether this activation is both maintained by a wild-type Ras/ phosphatidylinositol 3-kinase (PI3K)/Akt-positive feedback loop in endothelial cells and affects tumor angiogenesis. We found that supplementation of $\mathrm{BH} 4$ (via the pterin salvage pathway with Sep) increased Akt/eNOS phosphorylation in both human eNOS-transfected COS-7 cells and endothelial cells concomitant with increases in NO production, cell proliferation, migration, and tube formation. This augmentation was abrogated by a PI3K inhibitor. Sepiapterin (Sep) also increased GTP-bound wild-type Ras and PI3K/Akt/ eNOS activation, which was prevented by the eNOS inhibitor, N $\omega$-Nitro-L-arginine methyl ester (L-NAME). Furthermore, expression of GTP cyclohydrolase I (the rate-limiting enzyme in de novo BH4 synthesis) under doxycycline control potentiated in vivo tumorigenesis, tumor cell proliferation, as well as angiogenesis. Conversely, both switching off GTP cyclohydrolase I expression as well as inhibiting its enzymatic activity significantly decreased eNOS expression and tumor vascularization. This study demonstrates an important role for BH4 synthesis in angiogenesis by the activation of eNOS for NO production, which is maintained by a PI3K/Akt-positive feedback loop through effects on wild-type Ras in endothelial cells. Our findings suggest that BH4 syn- thesis may be a rational target for antiangiogenesis therapy for tumors. (Am J Pathol 2010, 177:2671-2680; DOI: 10.2353/ajpath.2010.100025)

Growth of new blood vessels from pre-existing ones, ensuring oxygen and nutrient supplies, is a crucial step in tumor cell proliferation, growth, and metastasis. This pathological angiogenesis is maintained by overproduction of proangiogenic factors, which act via a variety of signaling pathways in tumor stroma. ${ }^{1}$ Recent evidence suggests that nitric oxide (NO) provides crucial signals for angiogenesis in the tumor microenvironment, where moderate levels of NO are proangiogenic, $^{2,3}$ chiefly increasing DNA synthesis, cell proliferation and migration of endothelial cells to promote tumor angiogenesis. ${ }^{4}$

$\mathrm{NO}$ is a gaseous free radical, resulting from the conversion of L-arginine to citrulline by three distinct forms of NO synthase (NOS): endothelial NOS (eNOS), inducible NOS, and neuronal NOS in different cell types and tissues. ${ }^{5}$ eNOS is the principal isoform in tumor vascular endothelial cells. Under pathological conditions, eNOSderived $\mathrm{NO}$ is the dominant stimulus to angiogenesis in B16 melanomas. ${ }^{6}$ Inhibition of basal eNOS by caveolin-1, a protein that sequesters eNOS in caveolae, attenuates $\mathrm{NO}$-dependent blood flow in tumors and delays their growth as xenografts. ${ }^{7}$ Similarly, tumor growth is enhanced in caveolin-1-deficient mice because of increased microvascular permeability and angiogenesis. ${ }^{8}$ Inhibiting eNOS with L-arginine analogs ( $\mathrm{N} \omega$-NitroL-arginine methyl ester [L-NAME], NG-Methyl-L-arginine [L-NMMA] and N $\omega$-Nitro-L-arginine [L-NNA]) decreases both tumor blood flow and microvascular permeability in breast cancer xenografts. ${ }^{4}$ Moreover, a Phase I clinical trial has confirmed that L-NNA mark-

Supported by the Oxford University Challenge Seed Fund and Cancer Research UK.

Accepted for publication July 21, 2010

Address reprint requests to Shijie Cai, M.D., Ph.D., Departments of Clinical Pharmacology, University of Oxford, Old Road Campus Research Building, Roosevelt Drive, Headington, Oxford OX3 7DQ, UK. E-mail: shijie.cai@ clinpharm.ox.ac.uk. 
edly reduces blood flow in tumors. ${ }^{9}$ This suggests that eNOS-derived NO signaling is one of the key factors in maintaining blood flow and inducing vascular hyperpermeability for tumor progression.

eNOS activation for NO production can be induced by the proangiogenic vascular endothelial growth factor, undergoing complex phosphorylation modulation in endothelial cells. ${ }^{10}$ In response to vascular endothelial growth factor stimulation, phosphatidylinositol 3-kinase (PI3K) class $1 \mathrm{~A}$, comprising two heterodimers of regulatory $(p 85 \alpha)$ and catalytic $(p 110 \alpha)$ subunits, is recruited to the plasma membrane where Akt is phosphorylated. The activated Akt directly phosphorylates eNOS, leading to the transiently increased NO production. ${ }^{11}$ This regulatory free radical participates in signaling processes, fostering S-nitrosylation of a single cysteine residue (Cys ${ }^{118}$ ) in wild-type Ras. The group of these small GTPases converts the inactive GDP-bound Ras to the active GTPbound that in turn, up-regulates PI3K/Akt and eNOS to maintain NO production. Although the formation of this positive feedback loop plays a crucial role in promoting tumor progression and T lymphocyte activation, ${ }^{12,13}$ its role in regulating endothelial cells for angiogenesis is still not explored.

eNOS redox activity requires tetrahydrobiopterin $(\mathrm{BH} 4)$ as a cofactor for NO production. ${ }^{14}$ When $\mathrm{BH} 4$ levels are inadequate, eNOS preferentially produces superoxide over $\mathrm{NO}^{15,16}$ and contributes to vascular oxidative stress and angiogenesis regulation. ${ }^{17-19} \mathrm{BH} 4$ is synthesized via either the de novo pathway — GTP cyclohydrolase I (GCH; EC 3.5.4.16) is the rate-limiting enzyme, converting GTP to dihydroneopterin triphosphate before final generation of $\mathrm{BH} 4$ by sepiapterin (Sep) reductase; or the pterin salvage pathway-sepipaterin is a substrate. ${ }^{20}$ Essentially $\mathrm{BH} 4$ synthesis has been directly associated with activation of Akt and eNOS phosphorylation for NO production. ${ }^{21,22}$ However, the precise mechanism by which $\mathrm{BH} 4$ up-regulates phosphorylation of Akt and eNOS, and affects angiogenesis is not known.

Tumor progression is strongly influenced by environmental conditions and extracellular factors. GTP cyclohydrolase (GTPCH) gene expression is one of several distinct genes that are significantly up-regulated in the stromal fibroblasts in colon cancer-associated liver metastases. ${ }^{23}$ GTPCH activity favors tumor growth and is clearly increased in patients with malignant tumors, ${ }^{20,24}$ correlating strongly with recurrence of many cancers, particularly hematological and gynecological neoplasias, and lung, prostate, hepatocellular and gastrointestinal carcinoma. ${ }^{24-28}$ However, the role of GTPCH expression in tumor stromal fibroblasts, especially in regulating angiogenesis, remains to be elucidated.

The purposes of this study, therefore, were to determine the proangiogenic role of $\mathrm{BH} 4$ synthesis and its association with activation of eNOS and the wild-type Ras/PI3K/Akt pathway in endothelial cells in vitro and to evaluate the effects of GTPCH expression and $\mathrm{BH} 4$ synthesis in tumor stromal fibroblasts on angiogenesis in vivo.

\section{Materials and Methods}

\section{Reagents}

Sepiapterin (Sep) was purchased from Schircks Laboratories, and Ly294002 (LY) were obtained from Cell Signaling Technology (Beverly, MA), and dissolved in dimethyl sulfoxide (DMSO). 2,4-diamino-6-hydroxypyrimidine (DAHP) was purchased from Alexis Biochemicals (San Diego, CA) and dissolved in PBS.

\section{Cell Culture}

COS-7 and NIH3T3 Tet-off cells were grown in DMEM with $10 \%$ fetal bovine serum (FBS) in our laboratory, and primary human umbilical vein endothelial cells (HUVEC) were purchased from Lonza and grown in Endothelial Cell Growth Medium-2 (EGM-2) medium with bullet kit at $37^{\circ} \mathrm{C}$ in $5 \%$ $\mathrm{CO}_{2}$. HUVEC were used at passages 4 to 10. Before experiments, the cells were deprived of FBS for 3 to 4 hours for addition of reagents. All samples were determined in triplicate.

\section{Transfection}

Fifty percent of confluent monolayers of COS- 7 cells that are NOS deficient ${ }^{11}$ were transfected with the human eNOS plasmid DNA (provided by Prof. S. Dimmeler of University of Frankfurt, Frankfurt am, Germany) with Fugene 6 reagent (Roche Diagnostics).

\section{Western Blotting}

Western blot analysis was performed as described previously. ${ }^{15}$ Briefly, cells were lysed in radioimmunoprecipitation assay buffer $(50 \mathrm{mmol} / \mathrm{L}$ Tris- $\mathrm{HCl}(\mathrm{pH} 8)$ containing $0.2 \%$ Nonidet P-40, $180 \mathrm{mmol} / \mathrm{L} \mathrm{NaCl}, 0.5 \mathrm{mmol} / \mathrm{L}$ EDTA, $100 \mathrm{mmol} / \mathrm{L}$ phenylmethylsulforyl fluoride, and $1 \mathrm{M}$ dithiothreitol) containing phosphatase inhibitor (Roche Diagnostics). Equal amounts of cellular proteins were resolved by $12 \%$ SDS-PAGE and transferred to polyvinylidene difluoride membranes. Immunoblotting was performed using rabbit monoclonal antibodies (Cell Signaling Technology) to phosphor (p)-eNOS $\left(\mathrm{Ser}^{1177}\right)(1 /$ 1000), eNOS (1/2500), p-Akt (Ser $\left.{ }^{473}\right)(1 / 1000)$, Akt (1/2500), p-glycogen synthase kinase-3 beta (GSK3 $\beta ; 1 / 1000)$, and glyceraldehyde-3-phosphate dehydrogenase (GAPDH) (1/ 2500). Immunodetection was accomplished using the same donkey anti-rabbit secondary antibody (1/5000) (Promega, Madison, WI). Bands were visualized using chemiluminescence, and quantified using ImageJ software. For detecting active Ras (a GTP-bound state), we measured its ability to bind glutathione $S$-transferase fusion protein linked to the Raf fragment that contains the Ras-GTP binding domain GST-Raf-RBD. Lysates were cleared by centrifugation and incubated for 1 hour at $4^{\circ} \mathrm{C}$ with GST-Raf-RBD coupled to glutathione agarose beads and washed four times with lysis buffer. The beads containing GTP-bound Ras proteins were detected by Western blotting with pan-Ras antibody (Santa Cruz Biotechnology, Santa Cruz, CA). 


\section{Measurement of NO Production}

NO production in HUVEC was assayed using commercial $\mathrm{NO}$ detection kit (Bachem) as described previously. ${ }^{29}$ The cells $\left(1 \times 10^{5}\right.$ cells/well) were grown in 96-well plates and stained with diaminofluoresceine-diacetate (2DA), a fluorescent probe, for $\mathrm{NO}$ at $37^{\circ} \mathrm{C}$ for 30 minutes, and scanned on a fluorescence plate reader.

Determination of biopterins in cell and tissue lysates was carried out as described previously. ${ }^{15}$ Briefly, cell pellets or tissue frozen sections were lysed in cold extract buffer (50 mmol/L Tris- $\mathrm{HCl}$ (pH 7.4), $1 \mathrm{mmol} / \mathrm{L}$ dithiothreitol, $1 \mathrm{mmol} / \mathrm{L}$ EDTA). Protein concentration was measured using the Bio-Rad protein assay. Proteins were removed by adding $10 \mu \mathrm{l}$ of a $1: 1$ mixture of $1.5 \mathrm{M} \mathrm{HClO}_{4}$ and $2 \mathrm{M} \mathrm{H}_{3} \mathrm{PO}_{4}$ to $90 \mu \mathrm{l}$ of extracts, followed by centrifugation. To determine total biopterins $(\mathrm{BH} 4, \mathrm{BH} 2$, and biopterin) by acid oxidation $10 \mu$ l of $1 \%$ iodine in $2 \%$ potassium iodide $(\mathrm{KI})$ solution was added to $90 \mu \mathrm{l}$ protein-free supernatant. To determine $\mathrm{BH} 2$ and biopterin by alkaline oxidation, we added $10 \mu \mathrm{l}$ of $1 \mathrm{M} \mathrm{NaOH}$ to $80 \mu \mathrm{l}$ of extract and then $10 \mu \mathrm{l}$ of iodine/potassium iodide (KI) solution. Samples were incubated at room temperature for 1 hour in the dark. Alkaline-oxidation samples were then acidified with $20 \mu \mathrm{l}$ of $1 \mathrm{M} \mathrm{H}_{3} \mathrm{PO}_{4}$. lodine was reduced by adding $5 \mu \mathrm{l}$ of fresh ascorbic acid $(20 \mathrm{mg} / \mathrm{ml})$. Next, high-performance liquid chromatography was performed using a Spherisorb ODS-1 column (Waters, Elstree, UK) with a $10 \%$ methanol $/ 90 \%$ water mobile-phase run at $0.4 \mathrm{ml} / \mathrm{min}$. Fluorescence detection (350 nm excitation, 450 $\mathrm{nm}$ emission) was measured on an RF-10A $A_{X L}$ detector (Shimadzu, Kyoto, Japan). BH4 concentrations, expressed as picomoles per milligram protein, were calculated by subtracting $\mathrm{BH} 2+$ biopterin from total biopterins.

\section{Cell Proliferation}

HUVEC were plated at $5 \times 10^{4}$ cells/well in $1 \%$ of gelatincoated 12-well plates and cultured in Endothelial Cell Growth Medium-2 (EGM-2) with 10\% FBS without supplementing growth factors. Overnight after growth, cells were incubated in FBS-free medium with Sep $(10 \mu \mathrm{mol} /$ $\mathrm{L}) \pm \mathrm{LY}(10 \mu \mathrm{mol} / \mathrm{L})$ or the control (DMSO) for another 24 hours and counted with a Coulter counter (Beckman Coulter, Fullerton, CA).

\section{Cell Migration}

HUVEC were plated at $5 \times 10^{5}$ cells/well and cultured in Endothelial Cell Growth Medium-2 (EGM-2) with 2\% FBS and grown in growth factor-reduced Matrigel-precoated cell culture insert (8 $\mu \mathrm{m}$ pore size; Nunc, Naperville, IL). Cells that migrated overnight through the pores to the lower membrane were stained with Reastain Diff-Quick kit (Reagena), and five random fields were counted.

\section{Tubulogenesis}

Ninety-six-well culture plates were coated with $50 \mu \mathrm{l} /$ well of growth factor-reduced Matrigel (BD Biosciences, San
Jose, CA). HUVEC $\left(1 \times 10^{5} /\right.$ well) were incubated with $2 \%$ FBS for 24 hours, washed with PBS, and stained with 8 $\mu \mathrm{g} / \mathrm{ml}$ calcein-AM (Cambridge Bioscience, Cambridge, UK). Numbers of loops were counted in images taken at $\times 20$ magnification.

\section{Generation of Tetracycline-Regulated Human GTPCH Expression in Murine Fibroblast Cells}

An N-terminal HA epitope-tagged human GTPCH1 gene was cloned into pTet-off plasmid that contains tetracycline responsive element under cytomegalovirus promoter control. We transfected this plasmid DNA into NIH3T3 Tet-off cells that stably express tetracycline-controlled transactivator. ${ }^{30}$ In the presence of doxycycline (Dox), the tetracycline-controlled transactivator is blocked and incapable of binding to tetracycline responsive element, and therefore, activation of GTPCH1 gene is prevented. After three rounds of hygromycin selection, cells expressing HA-tagged human GTPCH (HA-GTPCH) and responding to various doses of Dox inhibition were established from expansion and termed "GCHtet-off," whereas control cells with empty vector transfection alone was termed "Tet-off-EV."

\section{Fibroblast Implantation}

GCHtet-off or Tet-off-EV in $100 \mu$ of $1 \times 10^{7}$ cell suspensions with an equal volume of Matrigel (BD Biosciences) were injected subcutaneously into flanks of 6- to 8-weekold female BALB/c SCID mice (Harlan Sprague Dawley, Indianapolis, IN) $(n=5)$. Growth tumors were measured two to three times per week using calipers, and volumes were calculated as (length $\times$ width $\times$ height) $/ 0.52$. When tumors reached the maximum size $\left(1.44 \mathrm{~cm}^{2}\right.$ surface area) permitted by the Home Office license, the mouse was sacrificed, and the tumor was excised. When needed, Dox in the drinking water $(2 \mathrm{~g} / \mathrm{L})$ with $5 \%$ of sucrose or DAHP (an inhibitor of GTPCH for de novo BH4 synthesis) i.p. injection (300 mg/kg/day) was given for 7 days starting from day 25 when tumor volumes reached $100 \mathrm{~mm}^{3}$. All mouse studies were conducted in accordance with protocols approved by the UK Home Office.

\section{Immunohistochemistry}

Paraffin-embedded tissue blocks from formalin-fixed tumor samples were sectioned, dewaxed, and rehydrated following standard protocols. Sections were stained for Ki-67, a marker of cell proliferation, with rat anti-mouse mindbomb homolog 1 (MIB-1) primary antibody (1/100) and rabbit anti-rat horseradish peroxidase antibody (1/ 200) (DakoCytomation, Glostrup, Denmark), and the positive cells counted in five randomly chosen fields. For CD34, a marker of angiogenesis, we used rat anti-mouse CD34 primary antibody (Serotec, Oxford, UK) and rabbit anti-rat horseradish peroxidase antibody (DakoCytomation) and quantified microvessel densities by the Chalkley method by defining three hotspot fields of 
vessels per section and five sections per tumor as published previously. ${ }^{31}$ Expression of HA-GTPCH in tumor was stained with rat anti-HA high affinity primary antibody (Roche Diagnostics) and rabbit anti-rat horseradish peroxidase antibody (DakoCytomation).

\section{Statistics}

Results are expressed as mean \pm SEM Statistical significance of differences between means was assessed using analysis of variance (ANOVA), followed by Student's unpaired two-tailed $t$-test and Bonferroni correction. A $P$ value of $<0.05$ was considered significant.

\section{Results}

\section{Phosphorylation of eNOS and Akt by BH4 Synthesis via PI3K Pathway}

To evaluate effects of $\mathrm{BH} 4$ synthesis on eNOS and Akt phosphorylation, we initially used COS cells that were transiently transfected with a human eNOS plasmid DNA.
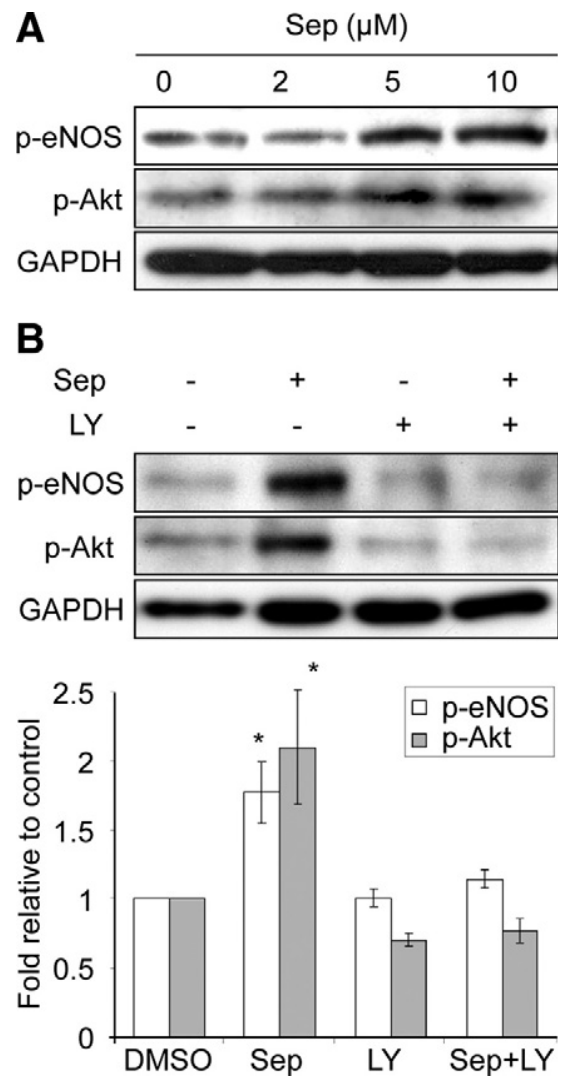

Figure 1. Phosphorylation of eNOS and Akt by BH4 synthesis depends on PI3K signaling in COS-7 cells and HUVEC. After overnight culture without FBS, human eNOS-transfected COS-7 cell monolayers were incubated for 30 minutes with Sep at various doses $(0,2,5$, and $10 \mu \mathrm{mol} / \mathrm{L})$ or the control (DMSO). Lysates were fractionated by SDS-PAGE and immunoblotted with monoclonal antibody to p-eNOS $\left(\operatorname{Ser}^{1177}\right)$, p-Akt $\left(\operatorname{Ser}^{473}\right)$, and GAPDH (A) HUVEC were cultured and pre-treated in Endothelial Cell Growth Medium-2 (EGM-2) without FBS. Lysates were analyzed as for COS-7 cells (B). Bands intensity of p-eNOS and p-Akt were quantified on ImageJ software. Data are shown as the mean \pm SEM $\left({ }^{*} P<0.05\right.$ vs. the control or Sep+LY, $\left.n=4\right)$ (ANOVA).
Table 1. Effect of Sepiapterin on Cellular Biopterin Production in Vascular Endothelial Cells

\begin{tabular}{lcc}
\hline \multicolumn{1}{c}{ Condition } & $\begin{array}{c}\text { Total biopterin } \\
(\mathrm{pmol} / \mathrm{mg})\end{array}$ & $\begin{array}{c}\mathrm{BH} 4 \\
(\mathrm{pmol} / \mathrm{mg})\end{array}$ \\
\hline HUVEC (DMSO) & $2.2 \pm 0.13$ & $0.7 \pm 0.07$ \\
Sep & $45.8 \pm 18.8^{*}$ & $9.6 \pm 4.6^{*}$ \\
LY & $2.1 \pm 0.9$ & $0.79 \pm 0.06$ \\
Sep+LY & $52.1 \pm 22.0$ & $10.1 \pm 4.3$ \\
\hline
\end{tabular}

HUVEC were incubated with Sep $(10 \mu \mathrm{mol} / \mathrm{L})$ for 30 minutes with or without pretreatment of $L Y(10 \mu \mathrm{mol} / \mathrm{L})$ for 1 hour or the vehicle control (DMSO). Cell pellets were harvested, and biopterin levels were determined by high-performance liquid chromatography using both acid-base oxidation with fluorometric detection. Values shown are the means \pm SEM of two triplicate determinations $\left(n=6,{ }^{*} P<0.05\right.$ vs. vehicle control, or LY determined by ANOVA).

The cells were incubated for 30 minutes with graded doses of Sep in serum-free medium, and lysates were analyzed by immunoblotting for eNOS and Akt proteins. Sep clearly increased phosphorylation of eNOS $\left(\operatorname{Ser}^{1177}\right)$ and endogenous Akt $\left(\mathrm{Ser}^{473}\right)$ in a dose-dependent manner (Figure 1A).

\section{BH4 Promotes HUVEC Proliferation, Migration, and Tubule Formation Via PI3K Signaling}

We then assessed the role of this pathway in regulating biological functions of human endothelial cells. As shown in Table 1, Sep greatly increased intracellular $\mathrm{BH} 4$ synthesis and enhanced eNOS Ser ${ }^{1177}$ and Akt Ser ${ }^{473}$ in HUVEC (Figure 1B), as in the COS cells. This augmentation required PI3K signaling, as it was prevented by LY (Figure 1B), independently of BH4 synthesis (Table 1).

Moreover, Sep not only augmented NO production by $50 \%$, but also significantly increased cell proliferation by $20 \%$, cell migration and tubule formation by $3.5-$ and 2.5-fold, respectively (Figure 2, A-D). Since pretreatment with LY inhibited each of these responses (Figure 2, A-D), the induction of HUVEC proliferation, migration and tubule formation by $\mathrm{BH} 4$ is apparently mediated by $\mathrm{NO}$ production, dependent on the PI3K signaling.

\section{Activation of the Wild-Type Ras Protein and PI3K/Akt Pathway by BH4 Is Mediated by NO Signaling in Endothelial Cells}

To examine the mechanism of these responses further, we incubated HUVEC with Sep $\pm N \omega$-Nitro-L-arginine methyl ester (L-NAME; $10 \mu \mathrm{mol} / \mathrm{L})$, which specifically inhibits eNOS. ${ }^{15,32}$ We demonstrated that Sep increased GTP-bound wild-type Ras (Figure 3A) and up-regulated p $85 \alpha$ (a PI3K regulatory subunit) by $40 \%(n=4)$ (Figure 3B). This augmentation correlated with increased levels of both eNOS Ser ${ }^{1177}$ and Akt Ser ${ }^{473}$ (Figure 3C). In contrast, $\mathrm{N} \omega$-Nitro-L-arginine methyl ester (L-NAME) pretreatment significantly decreased Sep-induced p85 $\alpha$ expression and eNOS/Akt phosphorylation by at least 30\% (Figure 3, B and C). Our results suggest that increased $\mathrm{BH} 4$ synthesis leading to the wild-type Ras activation and 

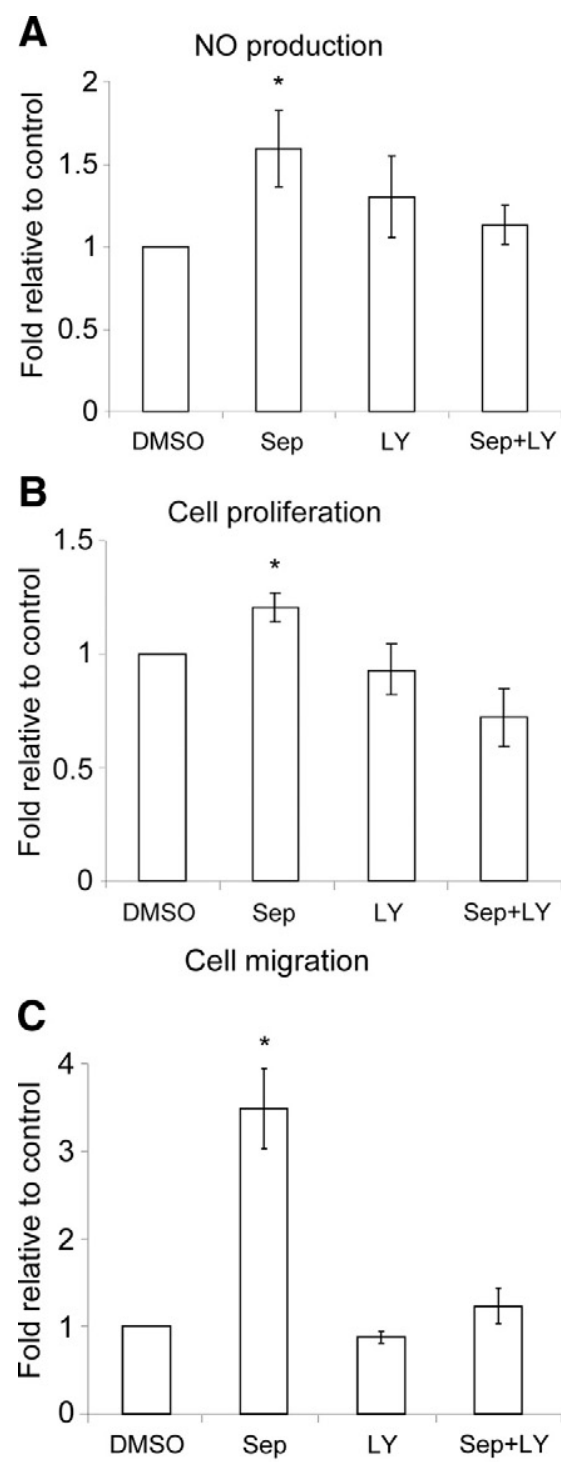

D Tubule formation
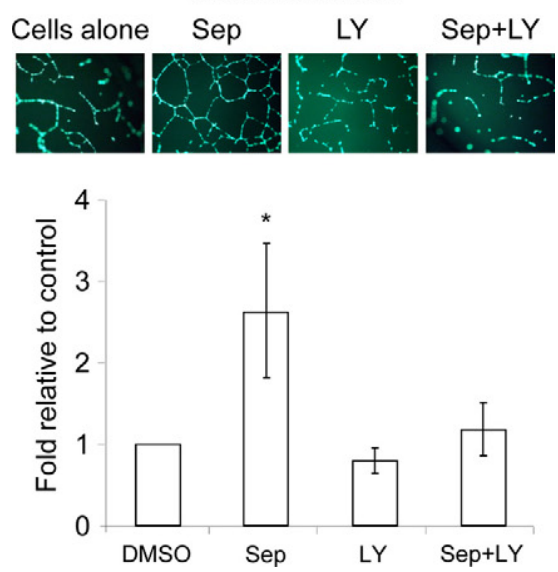

Figure 2. Sep-induced NO production and cell proliferation, migration, and tubule formation are dependent on PI3K signaling in HUVEC. A: Cells were cultured and pretreated as for Figure 1. B-D: For proliferation $(\mathbf{B})$, migration (C), and tubule formation at $\times 20$ magnification (D), cells were incubated with Sep $(10 \mu \mathrm{mol} / \mathrm{L}) \pm \mathrm{LY}(10 \mu \mathrm{mol} / \mathrm{L})$ or the control (DMSO) for 24 hours. Data are shown as the mean \pm SEM $\left({ }^{*} P<0.05\right.$ vs. the control or Sep + LY, $n=6$ ) (ANOVA). p85 $\alpha /$ Akt/eNOS up-regulation is mediated by NO signaling in HUVEC.

Taken together, our data show that intracellular $\mathrm{BH} 4$ synthesis promotes $\mathrm{Pl} 3 \mathrm{~K}$-dependent phosphorylation of Akt/eNOS, with a corresponding increase in endothelial cell proliferation, migration and tubule formation. Moreover, the consequent elevation of $\mathrm{NO}$ is paralleled by activating of endogenous wild-type Ras and PI3K signaling as proposed in Figure 3D. Indeed, we suggest that $\mathrm{BH} 4$ synthesis for $\mathrm{NO}$ production in endothelial cells is maintained by a wild- type Ras/PI3K/Akt-positive feedback loop. This novel mechanism is potentially important for angiogenesis induction.

\section{Effects of GTPCH Expression and BH4 Synthesis in Tumor Stromal Fibroblasts on Angiogenesis in Vivo}

To determine the proangiogenic potential of GTPCH expression for $\mathrm{BH} 4$ synthesis in tumor stromal fibroblasts, we implanted BALB/c SCID mice with GCHtet-off and 3T3tet-off-EV (as control), respectively (Figure 4A). We demonstrated that GTPCH expression not only increased fibroblast cell proliferation in tumor stroma (Figure 4B) but also transformed them as they formed tumors (Figure $4 A)$. They appeared by day 25 and grew rapidly to the permitted maximum at day 37 (Figure 4B). By contrast, 3T3tet-off-EV tumor stroma rarely generated even small nodules by day 43 (Figure 4A). By immunohistochemical staining, the GCHtet-off showed fourfold greater Ki-67 (proliferation marker) and CD34 (angiogenesis marker) counts than the 3T3tet-off-EV (Figure 4, B and C).

To demonstrate these effects specifically correlating with GTPCH expression and $\mathrm{BH} 4$ synthesis in tumor stromal fibroblasts, we then implanted BALB/c SCID mice with GCHtet-off, where we could control GTPCH expression in vivo similarly to in vitro (Figure 5A). Mice with tumors that had grown to $\sim 100 \mathrm{~mm}^{3}$ were then fed with Dox in drinking water to switch off GTPCH expression or injected with DAHP for 7 days to inhibit GTPCH enzymatic activity. The mice were sacrificed and tumors were harvested. Both immunohistochemical staining and Western blotting confirmed down-regulation of HAGTPCH expression by Dox (Figure 5, B and D). Moreover, we observed a concomitant $40 \%$ reduction in CD34-positive microvessel counts with Dox and 60\% reduction with DAHP (Figure $5 \mathrm{C}$ ). Western blotting analysis also showed 50 and $60 \%$ reduction of eNOS expression in Dox- or DAHP-treated tumors, respectively (Figure 5D), whereas iNOS was undetectable in both untreated and treated tumors (data not shown). These effects also correlated with a significant reduction of both total biopterin and $\mathrm{BH} 4$ in tumor stroma (Table 2). Our results suggest that expressing GTPCH for $\mathrm{BH} 4$ synthesis in tumor stromal fibroblasts has regulated the function of eNOS so that it controls microvessel formation.

Interestingly, $\mathrm{BH} 4$ levels remained elevated in DAHPtreated tumors and yet the microvessel density was lower than in Dox-treated tumors where $\mathrm{BH} 4$ levels were low (Table 2). To further understand the role of DAHP in tumor 
A

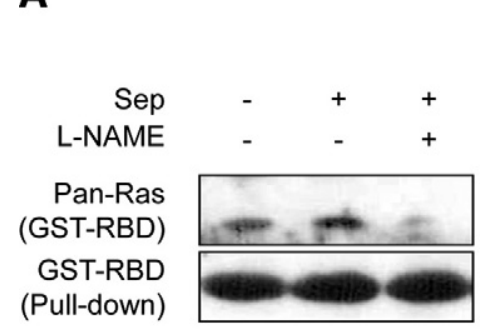

C

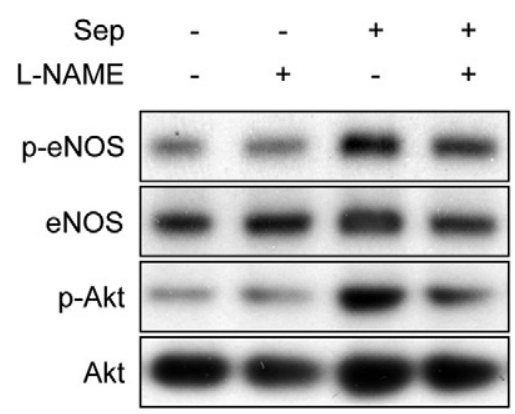

B

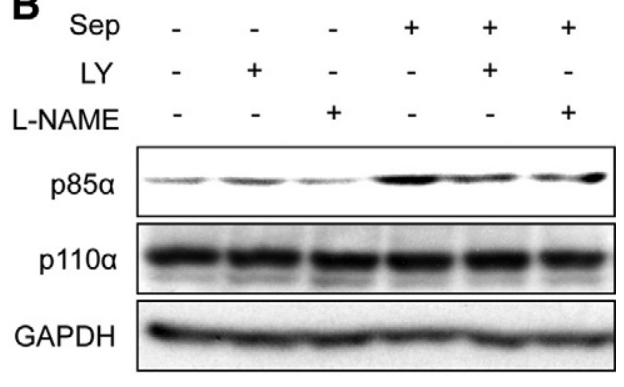

D Endothelial cells

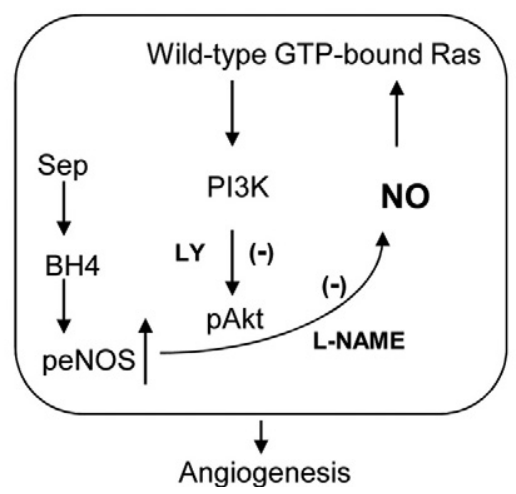

Figure 3. Sep-activated wild-type Ras cascade is mediated by NO in HUVEC. A: HUVEC were cultured and pretreated $\pm \mathrm{N} \omega$-Nitro-L-arginine methyl ester (L-NAME; $10 \mu \mathrm{mol} / \mathrm{L}$ ) or LY (10 $\mu \mathrm{mol} / \mathrm{L}$ ) for one hour. Lysates were then incubated with GST-Raf-RBD. After washing, the pull-down proteins by agarose beads were fractionated by SDS-PAGE and immunoblotted with pan-Ras antibody to GTP-bound Ras and GSTRaf-RBD. B and C: Lysates were also immunoblotted and analyzed for $\mathrm{p} 85 \alpha / \mathrm{p} 110 \alpha$, p-eNOS $\left(\operatorname{Ser}^{1177}\right)$, p-Akt $\left(\operatorname{Ser}^{473}\right)$, and GAPDH. D: Schematic diagram of proposing signaling. angiogenesis, we incubated HUVEC with DAHP overnight and analyzed the lysates by Western blotting. This showed down-regulation of both eNOS phosphorylation and expression in a dose dependent fashion (Figure 5E). These results suggest that increased antiangiogenic potency of DAHP is attributable to inhibiting $\mathrm{BH} 4$ synthesis and additionally down-regulating eNOS expression.

Surprisingly, however, the late impairment in tumor vessel formation with Dox or DAHP did not retard subsequent tumor growth or decrease Ki-67 expression (data not shown). Possibly, earlier treatment of smaller tumors might affect subsequent tumor growth, which was not obvious here. Nevertheless, these results establish that GTPCH expression and BH4 synthesis in the tumor stromal fibroblasts promotes the microvessel vessel formation, strongly supporting the in vitro findings that increased $\mathrm{BH} 4$ synthesis is a crucial factor for tumor angiogenesis induction.

\section{Discussion}

The present study demonstrates that $\mathrm{BH} 4$ synthesis via either the pterin salvage or the de novo pathway promotes endothelial cell proliferation, migration, and tubule formation in cultures and induces angiogenesis in tumor xenografts. These effects correlated with increases in eNOSproduced NO that depended, in turn, on the activation of wild-type Ras and its downstream PI3K/Akt effectors in vitro. Notably, genetically modified murine fibroblasts expressing GTPCH with concomitant increases in $\mathrm{BH} 4$ synthesis showed a novel effect of neoplastic transformation and induced tumor stromal fibroblast cell proliferation and microvessel formation in vivo.
Previous studies have shown that increasing $\mathrm{BH} 4$ synthesis can reverse the impaired proliferation found in endothelial cells that are derived from diabetic rat aortas. ${ }^{18}$ Conversely, indirectly decreasing $\mathrm{BH} 4$ levels by depleting intracellular GTP, a substrate for de novo $\mathrm{BH} 4$ synthesis, reduces NO production and inhibits both endothelial cell proliferation and tubule formation in vitro. ${ }^{19}$ However, a rigorous study of the molecular mechanisms by which $\mathrm{BH} 4$ promotes angiogenesis in in vitro and in vivo models remains unavailable. The present study clearly showed that $\mathrm{BH} 4$ enhances $\mathrm{NO}$ production in endothelial cells through the effects on wild-type Ras activation and the downstream PI3K/Akt signaling response. Furthermore, we established that GTPCH expression and $\mathrm{BH} 4$ synthesis in tumor stromal fibroblasts promotes angiogenesis in vivo.

There is compelling evidence that cellular $\mathrm{BH} 4$ levels govern eNOS catalytic activity. ${ }^{14,16,33}$ eNOS-derived NO can be induced by a variety of stimuli (including vascular endothelial growth factor), with extensive phosphorylation, ${ }^{10}$ dependent on the PI3K/Akt pathway. ${ }^{11,34}$ It was observed that $\mathrm{BH} 4$ synthesis increases phosphorylation of eNOS at Ser ${ }^{1177}$ in endothelial cells of the $\mathrm{GCH}$-transgenic mouse model, with human GTPCH expressed specifically in endothelial cells, leading to NO-mediated vasodilatation. ${ }^{21}$ In contrast, because inhibition of de novo $\mathrm{BH} 4$ synthesis by DAHP increases $\mathrm{Thr}^{497}$ phosphorylation rather than Ser ${ }^{1177}$, eNOS preferentially produces superoxide rather than $\mathrm{NO}$ in mouse cardiac myocytes. ${ }^{35}$ Moreover, GTPCH knockdown impairs vascular endothelial growth factor-initiated induction of eNOS activity, accompanied with eNOS dephosphorylation at Ser ${ }^{116}$; the activity is restored by reconstituting $\mathrm{BH} 4$ in bovine endo- 
A

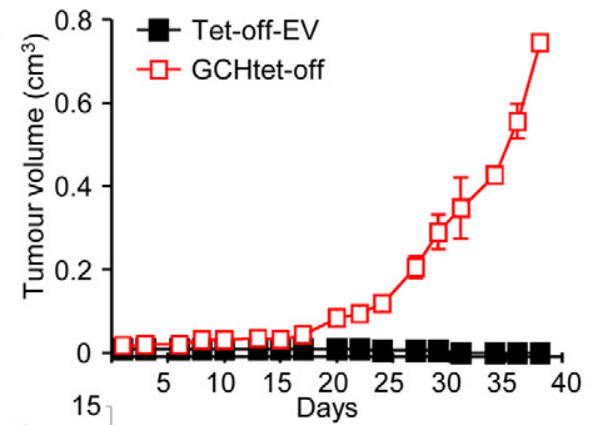

B

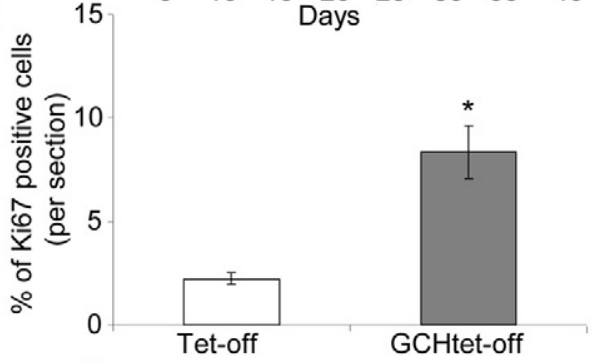

C

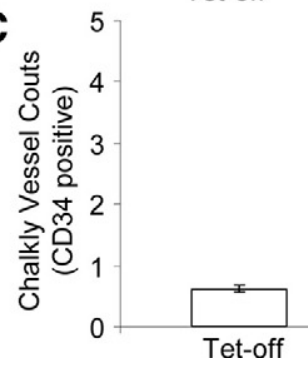

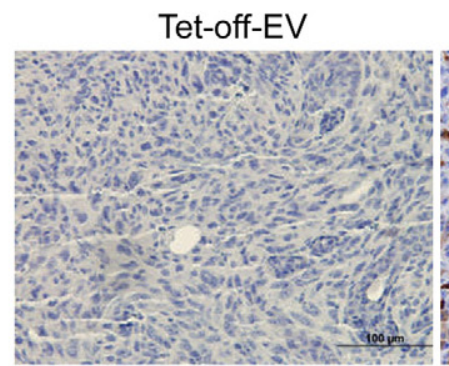
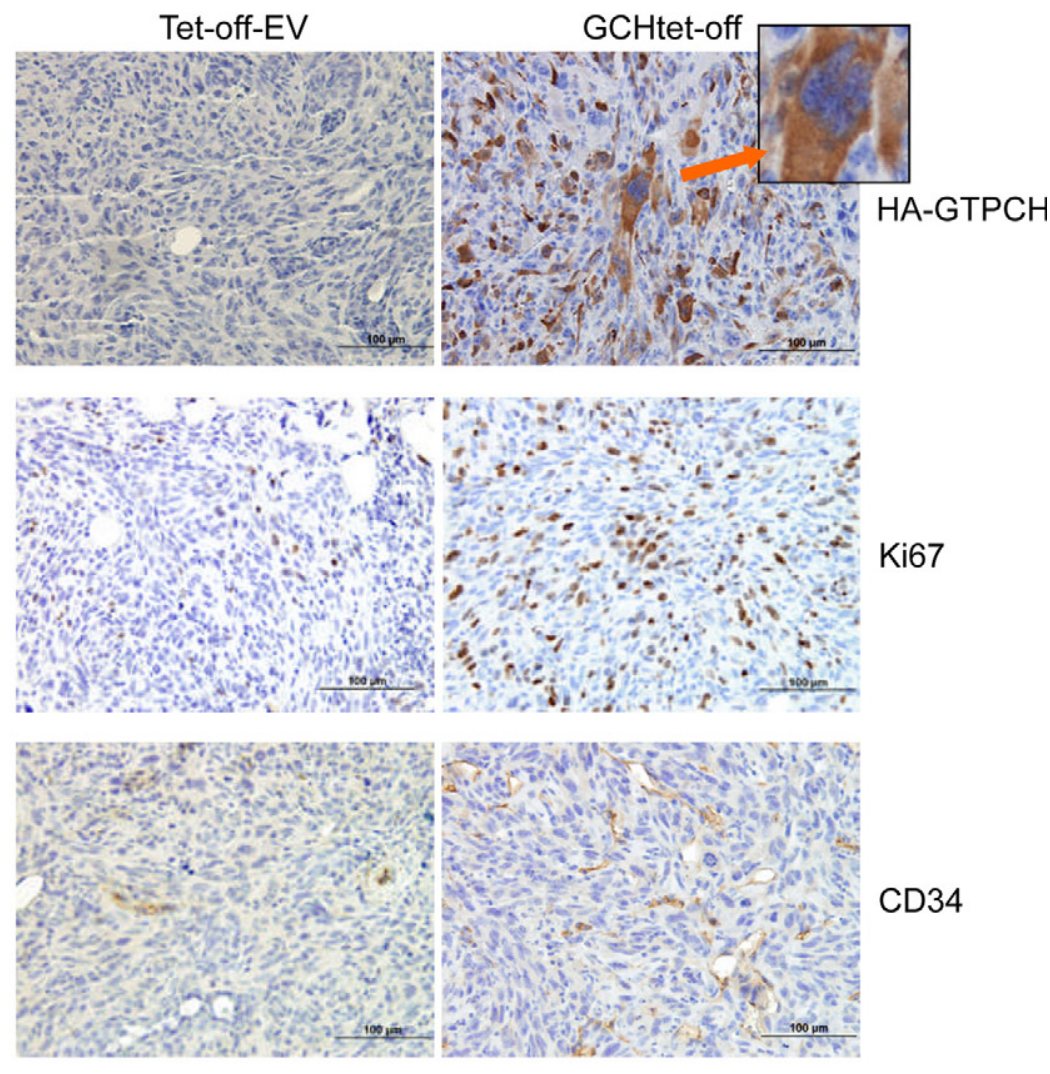

$\mathrm{CD} 34$

Figure 4. GTPCH overexpression and BH4 synthesis promote angiogenesis and tumor formation in mice. GCHtet-off cells $\left(1 \times 10^{7}\right)$ were injected s.c. into flanks of 6 - to 8-week-old female BALB/c SCID mice $(n=5)$ and Tet-off-EV as control. Tumor volumes were monitored two to three times per week (A), when they reached to maximum permitted volumes, mice were sacrificed, and tumors were sectioned and stained immunohistochemically for HA-GTPCH (red arrow-tumor cells) (A), Ki-67 (B), and CD34 (C) at $\times 20$ magnification. Data are shown as the mean of five sections per animal \pm SEM $\left({ }^{*} P<0.05\right.$ vs. Tet-off-EV, $\left.n=5\right)$ (ANOVA).

thelial cells. ${ }^{22}$ However, these observations only suggest the links of $\mathrm{BH} 4$ synthesis in modulating eNOS. How changes of $\mathrm{BH} 4$ synthesis modulate eNOS and Akt phosphorylation, and regulate angiogenesis, is still not clear.

The present study shows that the $\mathrm{BH} 4$ pterin salvage synthetic pathway increases phosphorylation of both Akt and eNOS in a dose-dependent manner in eNOS-transfected COS cells. This effect depends on PI3K, as does $\mathrm{BH} 4$ induced HUVEC proliferation, migration and tubule formation. Our data then suggest that PI3K is one of intermediate signaling pathways necessary for $\mathrm{BH} 4$-dependent NO production in endothelial cells.

This raises intriguing questions about how Sep augmented $\mathrm{BH} 4$ levels and the $\mathrm{PI} 3 \mathrm{~K}$ signaling interaction can modify phosphorylation of Akt and eNOS. Although the precise mechanisms by which Sep modifies Akt and eNOS phosphorylation in HUVEC remains to be formally proved, it is tempting to speculate that this occurs through the intermediate production of $\mathrm{NO}$ and consequently activation of wild-type Ras. Consistent with this possibility, it has been reported in tumors that eNOSderived NO provides crucial feedback signaling to substantially activate PI3K signaling for Akt phosphorylation, importantly mediated by wild-type Ras to favor oncogenic Ras activity and hence tumorigenesis. ${ }^{4,12}$
The three Ras isoforms ( $H, K$, and $N$-Ras) are small GTPases that convert the inactive GDP-bound Ras to the active GTP-bound form by recruiting Raf- 1 or PI3K to the plasma membrane to activate several key downstream effectors, principally Akt. ${ }^{36-38}$ By phosphorylating eNOS, Akt augments NO synthesis that in turn, is hypothesized to promote S-nitrosylation of cysteines of Ras proteins, ${ }^{12,13}$ as also occurs during activation of eNOStransfected T Iymphocytes. ${ }^{13}$ That reciprocally drives the PI3K/Akt pathway to maintain growth of tumors ${ }^{12}$ and concomitant angiogenesis. ${ }^{39,40}$ Moreover, deletion of $\mathrm{p} 85 \alpha$, a regulatory subunit of $\mathrm{PI} 3 \mathrm{~K}$, in mice has led to partially decreased GTPCH expression and $\mathrm{BH} 4$ synthesis activity, with subsequently attenuated NO production from iNOS in macrophages. ${ }^{41}$ Our study extends these findings, showing that $\mathrm{BH} 4$ synthesis via the pterin salvage pathway increases GTP-bound Ras and up-regulates the downstream effectors: p85 $\alpha$ and Akt/eNOS, dependent on NO signaling-supporting the notion that $\mathrm{BH} 4$ synthesis for $\mathrm{NO}$ production is maintained by a wild-type Ras/PI3K/Akt-positive feedback loop in endothelial cells.

We also evaluated the effects of GTPCH expression and $\mathrm{BH} 4$ synthesis in tumor stromal fibroblasts on angiogenesis in vivo. We demonstrated that GTPCH expression 
A

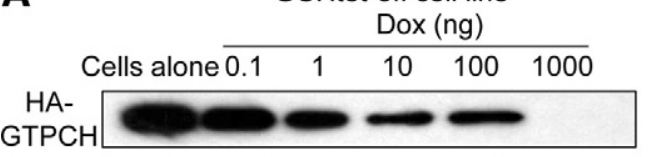

\section{Tumor microvessel formation}
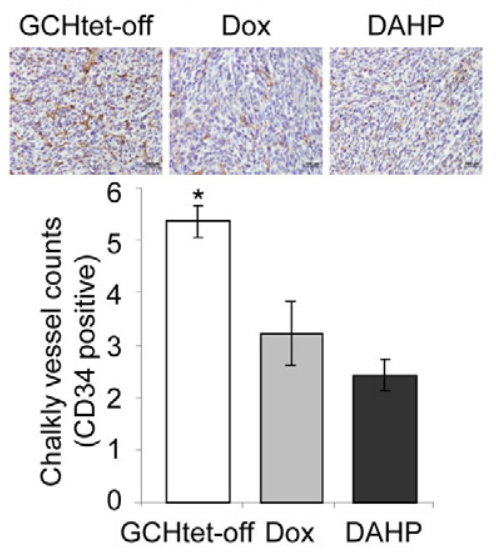

E

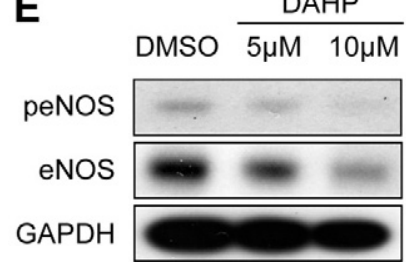

B

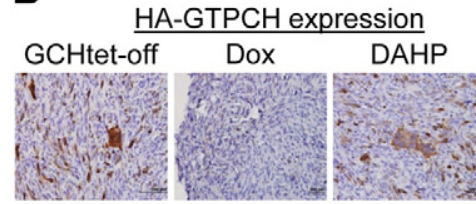

D
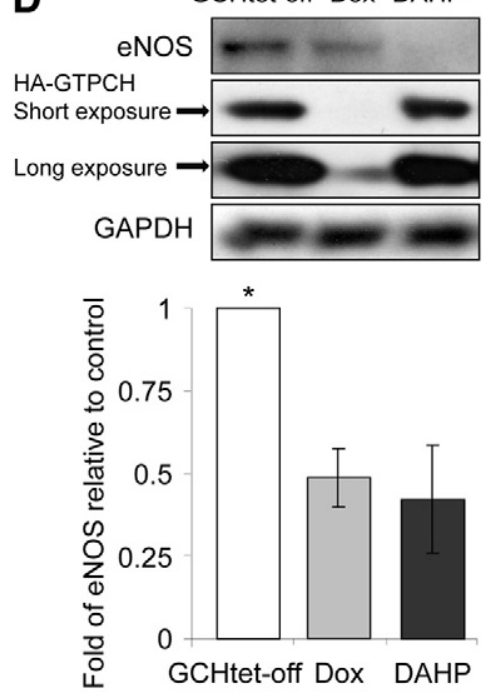

Figure 5. Both switch-off of GTPCH expression and inhibition of $\mathrm{BH} 4$ synthesis decrease angiogenesis in tumor stroma. HA-GTPCH expression is highly regulated by Dox in GCHtet-off cell line (A). GCHtet-off cells $\left(1 \times 10^{7}\right)$ were injected as for Figure 4 . When tumors reached to $100 \mathrm{~mm}^{3}$, mice were fed with Dox in the drinking water or i.p. injected with DAHP $(300 \mathrm{mg} / \mathrm{kg}$ of body weight) daily. After seven days, tumor sections were stained for HA-GTPCH (B) and CD34 (C) Data are shown as the mean of five sections per animal $\pm \operatorname{SEM}\left({ }^{*} P<0.05\right.$ vs. Dox or DAHP, $n=$ 5) (ANOVA) (C). Tissue homogenates were analyzed for eNOS, HA-GTPCH, and GAPDH $\left({ }^{*} P<\right.$ 0.05 vs. Dox or DAHP, $n=5$ ) (ANOVA) (D). HUVEC were incubated with graded doses of DAHP overnight, and lysates were assayed for p-eNOS $\left(\right.$ Ser $\left.^{1177}\right) /$ eNOS and GAPDH (representative of three experiments) (E) greatly increased $\mathrm{BH} 4$ synthesis and dramatically increased the stromal fibroblast cell proliferation and tumor vascularization, also strikingly transformed murine fibroblasts. In contrast, both switching off GTPCH expression and inhibiting its enzymatic activity selectively attenuated tumor vessel formation, associated with decreased eNOS expression and CD34 positive microvessels. These effects suggest a crucial role of GTPCH expression and $\mathrm{BH} 4$ synthesis in tumor stroma, where they potentiate tumor transformation and promote angiogenesis.

Intriguingly, we observed that in DAHP-treated tumors, $\mathrm{BH} 4$ levels remain substantial, but the microvessel densities are lower than in Dox-treated tumors. We hypothesized that there may be additional inhibitory effects of DAHP on tumor angiogenesis, independent on $\mathrm{BH} 4$ synthesis; we found that DAHP down-regulates eNOS protein expression in a dose-dependent manner, corre-

Table 2. GTPCH Overexpression Results in de Novo BH4 Synthesis in Murine Fibroblast Implantation

\begin{tabular}{lcc}
\hline Condition & $\begin{array}{c}\text { Total biopterin } \\
(\mathrm{pmol} / \mathrm{mg})\end{array}$ & $\begin{array}{c}\mathrm{BH} 4 \\
(\mathrm{pmol} / \mathrm{mg})\end{array}$ \\
\hline GCHtet-off & $216.1 \pm 35.9^{*}$ & $198.5 \pm 32.5^{*}$ \\
+ DOX & $23.7 \pm 3.2$ & $12.2 \pm 3.0$ \\
+ DAHP & $93.4 \pm 20.3$ & $81.0 \pm 19.1$ \\
\hline
\end{tabular}

GCHtet-off cells $\left(1 \times 10^{7}\right)$ were injected and treated with either Dox or DAHP as for Figure 5. Tumor tissues were homogenized, and biopterin levels were determined by high-performance liquid chromatography using both acid-base oxidation with fluorometric detection. Values shown are the means \pm SEM of animals $\left({ }^{*} P<0.05\right.$ vs. Dox or DAHP determined by ANOVA). sponding to decreased eNOS phosphorylation at $\mathrm{Ser}^{1177}$. DAHP is conventionally recognized as a specific competitive inhibitor of GTPCH as it has structural similarity to GTP. ${ }^{42}$ It also acts indirectly on GTPCH by directly binding to a GTPCH feedback regulatory protein to negatively inhibit GTPCH activity. ${ }^{43}$ A recent study has shown further that DAHP can nonspecifically down-regulate other proteins in HUVEC, including cytokine-induced expression of vascular cell adhesion molecule 1 and NF- $\kappa \mathrm{B} .{ }^{44}$ Clearly, our understanding roles of DAHP in antiangiogenesis in tumor remain preliminary. Additional investigation is needed to study these issues.

Yet we observed that antiangiogenesis targeting GT$\mathrm{PCH}$ expression and $\mathrm{BH} 4$ synthesis had not affected tumor stromal fibroblast cell proliferation or growth. This does not agree with several previous reports, where exogenously added $\mathrm{BH} 4$ promoted the proliferation of hemopoietic cells, mouse erythroleukemia and rat C6 glioma cells. ${ }^{45-47}$ That could reflect unexpected side effects of high doses of Sep (100 $\mu \mathrm{mol} / \mathrm{L})$ or nonspecific growth factor stimulation. Additionally, our work is on the stromal cells, rather than immortal fully transformed human cancer cell lines. Our manipulation of GTPCH might transform murine fibrolasts independently of $\mathrm{BH} 4$ synthesis, a possible mechanism is currently under investigation.

In conclusion, $\mathrm{NO}$ is a free radical with complex signaling actions in cancer. ${ }^{4}$ Emerging evidence suggests NOS activity in tumor vasculature can be a novel target for anticancer therapies. ${ }^{48} \mathrm{BH} 4$ is absolutely required for 
all NOS activity and is implicated in pathogenic actions of eNOS. ${ }^{14}$ Increasing BH4 synthesis was known to increase eNOS activity for NO production, ${ }^{49}$ thus enhancing tumor angiogenesis and growth. Here we show that increased eNOS activation results from a positive feedback mechanism through the effects of NO signaling on the wild-type Ras-PI3K/Akt pathway. Furthermore, augmented $\mathrm{BH} 4$ synthesis in vivo by GTPCH expression in tumor stromal fibroblasts strikingly potentiated tumor and microvessel formation, indicating novel actions of GTPCH on neoplastic transformation, tumor cell proliferation, and angiogenesis.

Importantly, these in vitro and in vivo findings imply that depleting $\mathrm{BH} 4$ levels in the tumor microenvironment, and thus reducing NOS activity, could inhibit tumor angiogenesis at the same time increasing production of tumorcytotoxic superoxide. Hence we now provide proof-ofprinciple that strategies targeting $\mathrm{BH} 4$ synthetic pathways may be a rational approach to inhibiting tumor angiogenesis and potentially tumor progression.

\section{References}

1. Carmeliet $P$, Jain RK: Angiogenesis in cancer and other diseases. Nature 2000, 407:249-257

2. Ridnour LA, Isenberg JS, Espey MG, Thomas DD, Roberts DD, Wink DA: Nitric oxide regulates angiogenesis through a functional switch involving thrombospondin-1. Proc Natl Acad Sci USA 2005, 102:13147-13152

3. Heller R, Polack T, Grabner R, Till U: Nitric oxide inhibits proliferation of human endothelial cells via a mechanism independent of cGMP. Atherosclerosis 1999, 144:49-57

4. Fukumura D, Kashiwagi S, Jain RK: The role of nitric oxide in tumour progression. Nat Rev Cancer 2006, 6:521-534

5. Stuehr DJ: Mammalian nitric oxide synthases. Biochim Biophys Acta 1999, 1411:217-230

6. Kashiwagi S, Izumi Y, Gohongi T, Demou ZN, Xu L, Huang PL, Buerk DG, Munn LL, Jain RK, Fukumura D: NO mediates mural cell recruitment and vessel morphogenesis in murine melanomas and tissueengineered blood vessels. J Clin Invest 2005, 115:1816-1827

7. Brouet A, DeWever J, Martinive P, Havaux X, Bouzin C, Sonveaux P, Feron $\mathrm{O}$ : Antitumor effects of in vivo caveolin gene delivery are associated with the inhibition of the proangiogenic and vasodilatory effects of nitric oxide. FASEB J 2005, 19:602-604

8. Lin MI, Yu J, Murata T, Sessa WC: Caveolin-1-deficient mice have increased tumor microvascular permeability, angiogenesis, and growth. Cancer Res 2007, 67:2849-2856

9. Ng QS, Goh V, Milner J, Stratford MR, Folkes LK, Tozer GM, Saunders MI, Hoskin PJ: Effect of nitric-oxide synthesis on tumour blood volume and vascular activity: a phase I study. Lancet Oncol 2007, 8:111-118

10. Fulton D, Gratton JP, Sessa WC: Posttranslational control of endothelial nitric oxide synthase: why isn't calcium/calmodulin enough? J Pharmacol Exp Ther 2001, 299:818-824

11. Fulton D, Gratton JP, McCabe TJ, Fontana J, Fujio Y, Walsh K, Franke TF, Papapetropoulos A, Sessa WC: Regulation of endothelium-derived nitric oxide production by the protein kinase Akt. Nature 1999, 399:597-601

12. Lim KH, Ancrile BB, Kashatus DF, Counter CM: Tumour maintenance is mediated by eNOS. Nature 2008, 452:646-649

13. Ibiza S, Perez-Rodriguez A, Ortega A, Martinez-Ruiz A, Barreiro O, Garcia-Dominguez CA, Victor VM, Esplugues JV, Rojas JM, SanchezMadrid F, Serrador JM: Endothelial nitric oxide synthase regulates $\mathrm{N}$-Ras activation on the Golgi complex of antigen-stimulated T cells. Proc Natl Acad Sci USA 2008, 105:10507-10512

14. Harrison DG: Cellular and molecular mechanisms of endothelial dysfunction. J Clin Invest 1998, 100:2153-2157

15. Cai S, Alp NJ, Mc Donald D, Canevari L, Heales S, Channon KM: GTP cyclohydrolase I gene transfer augments intracellular tetrahydrobiop- terin in human endothelial cells: effects on nitric oxide synthase activity, protein levels and dimerization. Cardiovasc Res 2002, 55:838-849

16. Cai S, Khoo J, Channon KM: Augmented BH4 by gene transfer restores nitric oxide synthase function in hyperglycemic human endothelial cells. Cardiovasc Res 2005, 65:823-831

17. Lowndes SA, Sheldon HV, Cai S, Taylor JM, Harris AL: Copper chelator ATN-224 inhibits endothelial function by multiple mechanisms. Microvasc Res 2009, 77:314-326

18. Marinos RS, Zhang W, Wu G, Kelly KA, Meininger CJ: Tetrahydrobiopterin levels regulate endothelial cell proliferation. Am J Physiol Heart Circ Physiol 2001, 281:H482-H489

19. Michaelis M, Michaelis R, Suhan T, Schmidt $H$, Mohamed A, Doerr HW, Cinatl J, Jr.: Ribavirin inhibits angiogenesis by tetrahydrobiopterin depletion. FASEB J 2007, 21:81-87

20. Thony B, Auerbach G, Blau N: Tetrahydrobiopterin biosynthesis, regeneration and functions. Biochem J 2000, 347(Pt. 1):1-16

21. Du YH, Guan YY, Alp NJ, Channon KM, Chen AF: Endotheliumspecific GTP cyclohydrolase I overexpression attenuates blood pressure progression in salt-sensitive low-renin hypertension. Circulation 2008, 117:1045-1054

22. Sugiyama T, Levy BD, Michel T: Tetrahydrobiopterin recycling, a key determinant of endothelial nitric-oxide synthase-dependent signaling pathways in cultured vascular endothelial cells. J Biol Chem 2009, 284:12691-12700

23. Nakagawa $H$, Liyanarachchi S, Davuluri RV, Auer H, Martin EW, Jr. de la Chapelle A, Frankel WL: Role of cancer-associated stromal fibroblasts in metastatic colon cancer to the liver and their expression profiles. Oncogene 2004, 23:7366-7377

24. Murr C, Widner B, Wirleitner B, Fuchs D: Neopterin as a marker for immune system activation. Curr Drug Metab 2002, 3:175-187

25. Weiss G, Kronberger P, Conrad F, Bodner E, Wachter H, Reibnegger G: Neopterin and prognosis in patients with adenocarcinoma of the colon. Cancer Res 1993, 53:260-265

26. Kronberger P, Weiss G, Tschmelitsch J, Fuchs D, Salzer GM, Wachter $\mathrm{H}$, Reibnegger G: Predictive value of urinary neopterin in patients with lung cancer. Eur J Clin Chem Clin Biochem 1995, 33:831-837

27. Murr C, Bergant A, Widschwendter M, Heim K, Schrocksnadel H, Fuchs D: Neopterin is an independent prognostic variable in females with breast cancer. Clin Chem 1999, 45:1998-2004

28. Melichar B, Solichova D, Svobodova I, Urbanek L, Vesely P, Melicharova K: Urinary neopterin in patients with liver tumors. Tumori 2006 , 92:318-322

29. Nanni S, Benvenuti V, Grasselli A, Priolo C, Aiello A, Mattiussi S, Colussi C, Lirangi V, Illi B, D'Eletto M, Cianciulli AM, Gallucci M, De Carli P, Sentinelli S, Mottolese M, Carlini P, Strigari L, Finn S, Mueller E, Arcangeli G, Gaetano C, Capogrossi MC, Donnorso RP, Bacchetti S, Sacchi A, Pontecorvi A, Loda M, Farsetti A: Endothelial NOS, estrogen receptor $\beta$, and HIFs cooperate in the activation of a prognostic transcriptional pattern in aggressive human prostate cancer. J Clin Invest 2009, 119:1093-1108

30. Gossen M, Bujard H: Tight control of gene expression in mammalian cells by tetracycline-responsive promoters. Proc Natl Acad Sci USA 1992, 89:5547-5551

31. Fox SB, Leek RD, Weekes MP, Whitehouse RM, Gatter KC, Harris AL: Quantitation and prognostic value of breast cancer angiogenesis: comparison of microvessel density, Chalkley count, and computer image analysis. J Pathol 1995, 177:275-283

32. Haendeler J, Hoffmann J, Tischler V, Berk BC, Zeiher AM, Dimmeler S: Redox regulatory and anti-apoptotic functions of thioredoxin depend on S-nitrosylation at cysteine 69. Nat Cell Biol 2002, 4:743-749

33. Zou MH, Shi C, Cohen RA: Oxidation of the zinc-thiolate complex and uncoupling of endothelial nitric oxide synthase by peroxynitrite. J Clin Invest 2002, 109:817-826

34. Dimmeler S, Fleming I, Fisslthaler B, Hermann C, Busse R, Zeiher AM: Activation of nitric oxide synthase in endothelial cells by Akt-dependent phosphorylation. Nature 1999, 399:601-605

35. Ceylan-Isik AF, Guo KK, Carlson EC, Privratsky JR, Liao SJ, Cai L, Chen AF, Ren J: Metallothionein abrogates GTP cyclohydrolase I inhibition-induced cardiac contractile and morphological defects: role of mitochondrial biogenesis. Hypertension 2009, 53:1023-1031

36. Downward J: The ras superfamily of small GTP-binding proteins. Trends Biochem Sci 1990, 15:469-472 
37. Schubbert S, Shannon K, Bollag G: Hyperactive Ras in developmental disorders and cancer. Nat Rev Cancer 2007, 7:295-308

38. Karnoub AE, Weinberg RA: Ras oncogenes: split personalities. Nat Rev Mol Cell Biol 2008, 9:517-531

39. Blume-Jensen P, Hunter T: Oncogenic kinase signalling. Nature 2001, 411:355-365

40. Vivanco I, Sawyers CL: The phosphatidylinositol 3-kinase AKT pathway in human cancer. Nat Rev Cancer 2002, 2:489-501

41. Sakai K, Suzuki H, Oda H, Akaike T, Azuma Y, Murakami T, Sugi K, Ito $\mathrm{T}$, Ichinose H, Koyasu S, Shirai M: Phosphoinositide 3-kinase in nitric oxide synthesis in macrophage: critical dimerization of inducible nitric-oxide synthase. J Biol Chem 2006, 281:17736-17742

42. Kolinsky MA, Gross SS: The mechanism of potent GTP cyclohydrolase I inhibition by 2,4-diamino-6-hydroxypyrimidine: requirement of the GTP cyclohydrolase I feedback regulatory protein. J Biol Chem 2004, 279:40677-40682

43. Xie L, Smith JA, Gross SS: GTP cyclohydrolase I inhibition by the prototypic inhibitor 2,4-diamino-6-hydroxypyrimidine: mechanisms and unanticipated role of GTP cyclohydrolase I feedback regulatory protein. J Biol Chem 1998, 273:21091-21098

44. Ikemoto K, Matsumoto T, Ohtsuki M, Itoh M, Tada S, Udagawa Y,
Sumi-Ichinose C, Kondo K, Nomura T: 2,4-Diamino-6-hydroxypyrimidine (DAHP) suppresses cytokine-induced VCAM-1 expression on the cell surface of human umbilical vein endothelial cells in a $\mathrm{BH}(4)$ independent manner. Biochim Biophys Acta 2008, 1780:960-965

45. Tanaka K, Kaufman S, Milstien S: Tetrahydrobiopterin, the cofactor for aromatic amino acid hydroxylases, is synthesized by and regulates proliferation of erythroid cells, Proc Natl Acad Sci USA 1989, 86:5864-5867

46. Kerler F, Ziegler I, Schmid C, Bacher A: Synthesis of tetrahydrobiopterin in Friend erythroleukemia cells and its modulator effect on cell proliferation. Exp Cell Res 1990, 189:151-156

47. Anastasiadis PZ, Bezin L, Imerman BA, Kuhn DM, Louie MC, Levine RA: Tetrahydrobiopterin as a mediator of PC12 cell proliferation induced by EGF and NGF. Eur J Neurosci 1997, 9:1831-1837

48. Kashiwagi S, Tsukada K, Xu L, Miyazaki J, Kozin SV, Tyrrell JA, Sessa WC, Gerweck LE, Jain RK, Fukumura D: Perivascular nitric oxide gradients normalize tumor vasculature. Nat Med 2008, 14:255-257

49. Hink U, Li H, Mollnau H, Oelze M, Matheis E, Hartmann M, Skatchkov M, Thaiss F, Stahl RA, Warnholtz A, Meinertz T, Griendling K, Harrison $D G$, Forstermann $U$, Munzel $T$ : Mechanisms underlying endothelial dysfunction in diabetes mellitus. Circ Res 2001, 88:E14-E22 